\title{
Influence of reaction piles on test pile response in a static load test*
}

\author{
Qian-qing ZHANG ${ }^{\dagger 1}$, Shu-cai LI ${ }^{1}$, Zhong-miao ZHANG ${ }^{2}$ \\ $\left({ }^{1}\right.$ Geotechnical and Structural Engineering Research Center, Shandong University, Jinan 250061, China) \\ $\left({ }^{2}\right.$ MOE Key Laboratory of Soft Soils and Geoenvironmental Engineering, Zhejiang University, Hangzhou 310058, China) \\ †E-mail: zqq5820948@126.com \\ Received Aug. 20, 2012; Revision accepted Jan. 2, 2013; Crosschecked Feb. 22, 2013
}

\begin{abstract}
This work presents a new analytical method to analyze the influence of reaction piles on the test pile response in a static load test. In our method, the interactive effect between soil and pile is simulated using independent springs and the shear displacement method is adopted to analyze the influence of reaction piles on test pile response. Moreover, the influence of the sheltering effect between reaction piles and test pile on the test pile response is taken into account. Two cases are analyzed to verify the rationality and efficiency of the present method. This method can be easily extended to a nonlinear response of an influenced test pile embedded in a multilayered soil, and the validity is also demonstrated using centrifuge model tests and a computer program presented in the literature. The present analyses indicate that the proposed method will lead to an underestimation of the test pile settlement in a static load test if the influence of the presence of reaction piles on the test pile response is neglected.
\end{abstract}

Key words: Test pile, Reaction pile, Shear displacement method, Sheltering effect, Multilayered soil doi: 10.1631 jzus.A1200210

Document code: A

CLC number: TU473.1

\section{Introduction}

To obtain a load-displacement response of a single pile, many forms of static load test can be used in practical applications. A test setup with reaction piles to supply reaction force has been widely used because of its great advantages of convenient installation and low cost. In China, most static load tests are carried out using a reaction system composed of anchor pile, bearing platform and reaction beam. The Chinese Technical Code (JGJ 106-2003) states that the center-to-center distance between the test pile and reaction piles should be four times the maximum diameter of the reaction piles or the test pile, and also not less than $2.0 \mathrm{~m}$. However, the measured test pile displacement may be influenced by the interactive effects between reaction piles and test pile during the whole loading cycle, as suggested by Poulos and

\footnotetext{
* Project supported by the China Postdoctoral Science Foundation (No. 2012M521339), and the Independent Innovation Foundation of Shandong University (No. 2012GN012), China

(C) Zhejiang University and Springer-Verlag Berlin Heidelberg 2013
}

Davis (1980), Latotzke et al. (1997), and Kitiyodom et al. (2004).

In a static load test, the load acted on the test pile is transferred to the soil around the piles with the help of the reaction piles. Since the load applied on the reaction piles leads to an opposite deformation of the test pile, as shown in Fig. 1, the measured displacement of the test pile is different from that of an individual pile loaded by the same load. Actually, the measured test pile displacement is less than the individual pile displacement, and the difference between the measured displacement and the individual pile displacement increases with decreasing center-tocenter distance between reaction piles and test pile.

In this work, the correction factor $F_{\mathrm{c}}$ defined as the ratio of initial stiffness of the influenced individual pile, $K_{\mathrm{G}}$, to initial stiffness of the non-influenced individual pile, $K_{\mathrm{i}}$, is adopted to describe the influence of reaction piles (Fig. 2). The analysis on the correction factor is valuable in leading to a better understanding of the influence of the reaction piles on the test pile behavior. Present methods considering the interactive effect among piles mainly include the 
load transfer method (Kraft et al., 1981; Guo, 2001), the elastic theory method (Poulos and Davis, 1980; Mylonakis and Gazetas, 1998; Poulos, 2001), the method based on energy principles (Klar and Leung, 2009), the finite element method ( $\mathrm{Xu}$ and Poulos, 2001; Reul and Randolph, 2003; de Sanctis and Mandolini, 2006) and various empirical methods. However, these interaction models are commonly utilized for piles of identical dimensions, and not suitable for piles with different diameters.

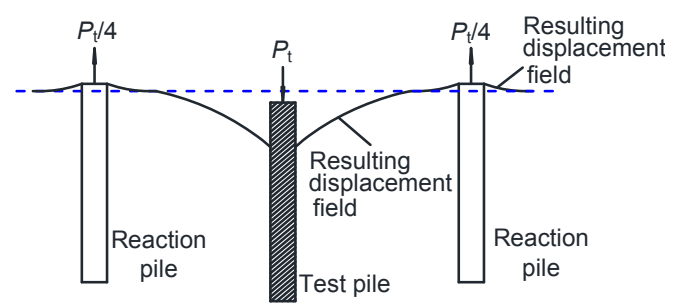

Fig. 1 Displacement of test pile and reaction piles due to interactions between test and reaction piles (four reaction piles)

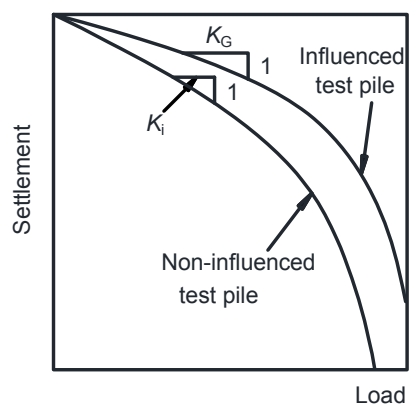

Fig. 2 Load-displacement responses of non-influenced individual pile and influenced pile (Kitiyodom et al., 2004)

Based on the results of static load tests conducted using two reaction piles, Poulos and Davis (1980) studied the correction factor for the initial pile head stiffness. Kitiyodom et al. (2004) analyzed the pile slenderness ratio, pile spacing ratio and pile soil stiffness ratio of four reaction piles on the test pile using a computer program PRAB. Experimental work conducted by Lu and Yang (2007) showed that the reaction piles could affect the bearing capacity of the test pile. In addition, the settlement obtained from the original test data was observed to be larger than the individual pile displacement. However, all the above-mentioned methods have one common limitation is that they do not consider the sheltering effect between piles on the test pile response.
This paper presents a new analytical method to analyze the influence of reaction piles on the test pile response in a static load test. In the present method, the interactive effect between soil and pile is simulated by independent springs, and the shear displacement method is also adopted. Furthermore, the influence of the sheltering effect between reaction piles and test pile on the test pile response is taken into account. Two cases presented by Kitiyodom et al. (2004) are used to verify the efficiency and accuracy of the present approach.

This approach can be easily extended to a nonlinear response of a single pile as described in Sections 5 and 6, and the validity of the proposed approach is demonstrated in Section 7. Note that in China, the working piles are often used as the reaction piles, and pile load tests are usually carried out using four reaction piles. Therefore, in this work the test pile diameter is assumed to be identical to the reaction pile diameter. Herein, the influence of the load applied on four reaction piles on the load-displacement response of the test pile is discussed in this paper.

\section{Initial pile head stiffness of single pile embedded in a multilayered soil}

In this study, an assumption is made that pile-soil relative slip does not exist. The shear displacement of the soil around the pile shaft caused by the skin friction leads to the shaft settlement. The control equation of the shaft settlement is as follows:

$$
\frac{\mathrm{d}^{2} w(z)}{\mathrm{d} z^{2}}-\frac{k w(z)}{E_{\mathrm{p}} A_{\mathrm{p}}}=0
$$

where $w(z)$ is the shaft settlement at a given depth $z$; $E_{\mathrm{p}}$ and $A_{\mathrm{p}}$ represent the pile's elastic modulus and the pile area, respectively; and $k$ is the spring stiffness of the soil around pile shaft according to the Winkler hypothesis (Randolph and Wroth, 1978), which is evaluated by

$$
k=\frac{2 \pi G}{\ln \left(r_{\mathrm{m}} / r_{0}\right)},
$$

where $G$ is the shear modulus of the soil around pile shaft; $r_{0}$ is the pile radius; and $r_{\mathrm{m}}$ is the radial distance 
from the pile centre to a point where the shear stress caused by the pile can be considered negligible. As suggested by Randolph and Wroth (1978), $r_{\mathrm{m}}$ can be expressed in terms of pile length $L$ as

$$
r_{\mathrm{m}}=2.5 L \rho_{\mathrm{m}}\left(1-v_{\mathrm{s}}\right)
$$

where $v_{\mathrm{s}}$ is the Poisson's ratio of the surrounding soil; and $\rho_{\mathrm{m}}$ is the modified non-homogeneity factor. For the pile embedded into a homogenous soil, $\rho_{\mathrm{m}}=$ $G_{2 / L} / G_{L}$, where $G_{2 / L}$ and $G_{L}$ is the shear modulus of the soil at a depth equal to half the pile length and the pile length, respectively. In an $n$-layer soil system, the pile elements are divided according to the distribution of soil layers along the pile embedded length, and $r_{\mathrm{m}}$ can be estimated as (Lee, 1991)

$$
r_{\mathrm{m}}=2.5 L\left\{\frac{\sum_{i=1}^{n} G_{i} L_{i}}{G_{\mathrm{m}} L} \sqrt{\frac{G_{\mathrm{m}}}{G_{\mathrm{b}}}}\left[1-\mathrm{e}^{\left(1-\frac{h}{L}\right)}\right]\right\}\left(1-v_{\mathrm{s}}\right)
$$

where $G_{\mathrm{m}}$ is the maximum shear modulus in the soil elements; $G_{i}$ is the shear modulus of soil layer $i ; L_{i}$ is the length of pile section embedded in soil layer $i ; G_{\mathrm{b}}$ is the soil shear modulus at the pile base; and $h$ is the finite soil depth.

The general solution of shaft settlement, $w(z)$, can be expressed as

$$
w(z)=c_{1} \mathrm{e}^{\mu z}+c_{2} \mathrm{e}^{-\mu z}
$$

where $\mu=\sqrt{k /\left(E_{\mathrm{p}} A_{\mathrm{p}}\right)}$, and $c_{1}, c_{2}$ are constants.

The axial force at a depth $z, P(z)$, is written as

$$
P(z)=-E_{\mathrm{p}} A_{\mathrm{p}} \mu\left(c_{1} \mathrm{e}^{\mu z}-c_{2} \mathrm{e}^{-\mu z}\right) .
$$

A matrix form of Eqs. (5) and (6) can be written as

$$
\left\{\begin{array}{l}
w(z) \\
P(z)
\end{array}\right\}=\left[\begin{array}{cc}
\mathrm{e}^{\mu z} & \mathrm{e}^{-\mu z} \\
-E_{\mathrm{p}} A_{\mathrm{p}} \mu \mathrm{e}^{\mu z} & E_{\mathrm{p}} A_{\mathrm{p}} \mu \mathrm{e}^{-\mu z}
\end{array}\right]\left\{\begin{array}{l}
c_{1} \\
c_{2}
\end{array}\right\} .
$$

Assume the pile is divided into $n$ segments. Taking the soil layer $i$ with a depth of $L_{i}$ as an example, the settlement and the load at the pile top and end, respectively, can be expressed in the following form:

$$
\begin{gathered}
\left\{\begin{array}{l}
w_{\mathrm{t}} \\
P_{\mathrm{t}}
\end{array}\right\}_{i}=\left[\begin{array}{cc}
1 & 1 \\
-E_{\mathrm{p}} A_{\mathrm{p}} \mu & E_{\mathrm{p}} A_{\mathrm{p}} \mu
\end{array}\right]\left\{\begin{array}{l}
c_{1} \\
c_{2}
\end{array}\right\}, \\
\left\{\begin{array}{l}
w_{\mathrm{b}} \\
P_{\mathrm{b}}
\end{array}\right\}_{i}=\left[\begin{array}{cc}
\mathrm{e}^{\mu L_{i}} & \mathrm{e}^{-\mu L_{i}} \\
-E_{\mathrm{p}} A_{\mathrm{p}} \mu \mathrm{e}^{\mu L_{i}} & E_{\mathrm{p}} A_{\mathrm{p}} \mu \mathrm{e}^{-\mu L_{i}}
\end{array}\right]\left\{\begin{array}{l}
c_{1} \\
c_{2}
\end{array}\right\} .
\end{gathered}
$$

The values of $c_{1}$ and $c_{2}$ can be calculated by

$$
\left\{\begin{array}{l}
c_{1} \\
c_{2}
\end{array}\right\}=\frac{1}{2 E_{\mathrm{p}} A_{\mathrm{p}} \mu}\left[\begin{array}{cc}
E_{\mathrm{p}} A_{\mathrm{p}} \mu \mathrm{e}^{-\mu L_{i}} & -\mathrm{e}^{-\mu L_{i}} \\
E_{\mathrm{p}} A_{\mathrm{p}} \mu \mathrm{e}^{\mu L_{i}} & \mathrm{e}^{\mu L_{i}}
\end{array}\right]\left\{\begin{array}{l}
w_{\mathrm{b}} \\
P_{\mathrm{b}}
\end{array}\right\}_{i} .
$$

By substituting Eq. (10) into Eq. (8), the relationships between the load and the settlement at the pile top and end of pile section $i$ can be expressed as

$$
\left\{\begin{array}{l}
w_{\mathrm{t}} \\
P_{\mathrm{t}}
\end{array}\right\}_{i}=\left[\begin{array}{cc}
\cosh \left(\mu L_{i}\right) & \frac{\sinh \left(\mu L_{i}\right)}{E_{\mathrm{p}} A_{\mathrm{p}} \mu} \\
E_{\mathrm{p}} A_{\mathrm{p}} \mu \sinh \left(\mu L_{i}\right) & \cosh \left(\mu L_{i}\right)
\end{array}\right]\left\{\begin{array}{l}
w_{\mathrm{b}} \\
P_{\mathrm{b}}
\end{array}\right\}_{i} .
$$

Using the transfer matrix method, one can obtain the relationship between load and settlement developed at the pile top and end:

$$
\begin{aligned}
\left\{\begin{array}{l}
w_{\mathrm{t}} \\
P_{\mathrm{t}}
\end{array}\right\} & =\prod_{i=1}^{n}\left[\begin{array}{cc}
\cosh \left(\mu L_{i}\right) & \frac{\sinh \left(\mu L_{i}\right)}{E_{\mathrm{p}} A_{\mathrm{p}} \mu} \\
E_{\mathrm{p}} A_{\mathrm{p}} \mu \sinh \left(\mu L_{i}\right) & \cosh \left(\mu L_{i}\right)
\end{array}\right]\left\{\begin{array}{l}
w_{\mathrm{b}} \\
P_{\mathrm{b}}
\end{array}\right\} \\
& =\boldsymbol{T}\left\{\begin{array}{l}
w_{\mathrm{b}} \\
P_{\mathrm{b}}
\end{array}\right\},
\end{aligned}
$$

where $w_{\mathrm{b}}$ is the settlement at the pile base, $P_{\mathrm{b}}$ is the mobilized base load, $w_{\mathrm{t}}$ is the pile head settlement, and $P_{\mathrm{t}}$ is the pile head load, and $\boldsymbol{T}$ is the load transfer matrix.

The soil stiffness at the pile base, $k_{\mathrm{b}}$, can be estimated as (Lee, 1991)

$$
k_{\mathrm{b}}=\frac{P_{\mathrm{b}}}{w_{\mathrm{b}}}=\frac{4 G_{\mathrm{b}} r_{0}}{\left(1-v_{\mathrm{b}}\right)} \frac{1}{\left[1-\mathrm{e}^{-h^{*} /\left(2 r_{\mathrm{o}}\right)}\right]},
$$

where $h^{*}$ is the distance from the pile end to the rigid bed stratum; and $v_{\mathrm{b}}$ is Poisson's ratio of the soil at the pile base.

The pile head settlement, $w_{t}$, is set to 1 , and the initial pile head load is assumed to be $K_{\mathrm{i}}$ which can be estimated as 


$$
K_{\mathrm{i}}=\frac{\boldsymbol{T}_{21}+\boldsymbol{T}_{22} k_{\mathrm{b}}}{\boldsymbol{T}_{11}+\boldsymbol{T}_{12} k_{\mathrm{b}}}
$$

where $\boldsymbol{T}_{i j}$ is the element of the row $i$ and column $j$ in the matrix $\boldsymbol{T}, i, j=1,2$.

\section{Initial pile head stiffness of an influenced test pile embedded in a multilayered soil}

The test pile displacement at a given depth below the ground surface is assumed to be $w_{\mathrm{t} 1}$, which consists of three parts. The first part, $w_{11}$, is the settlement induced by its own loading. The second part, $w_{12}$, is the displacement caused by the loads applied on the reaction pile because of the interactive effect. The third component, $w_{12}$, the reduction of displacement, is induced by the reinforcement effect of the pile due to the neighbouring load-free reaction pile.

The reaction pile displacement at a given depth below the ground surface, $w_{\mathrm{t} 2}$, is also composed of three parts: the settlement induced by its own loading, $w_{22}$; the displacement caused by the loads applied on the test pile because of the interactive effect, $w_{21}$; and the reduction of displacement induced by the reinforcement effect of the pile due to the adjacent load-free test pile, $w_{21}{ }^{\prime}$.

The displacements of the test pile and reaction pile at a given depth, $w_{\mathrm{t} 1}$ and $w_{\mathrm{t} 2}$, respectively, can be written as

$$
\left\{\begin{array}{l}
w_{\mathrm{t} 1}=w_{11}-\left(w_{12}-w_{12}^{\prime}\right) \\
w_{\mathrm{t} 2}=-\left(w_{21}-w_{21}^{\prime}\right)+w_{22}
\end{array}\right.
$$

A matrix form of Eq. (15) can be obtained:

$$
\left\{\begin{array}{l}
w_{\mathrm{t} 1} \\
w_{\mathrm{t} 2}
\end{array}\right\}=\left[\begin{array}{cc}
\delta_{11} & \delta_{12}^{\prime}-\delta_{12} \\
\delta_{21}^{\prime}-\delta_{21} & \delta_{22}
\end{array}\right]\left\{\begin{array}{l}
P_{\mathrm{t} 1} \\
P_{\mathrm{t} 2}
\end{array}\right\} .
$$

Eq. (16) can also be written as

$$
\left\{\begin{array}{l}
P_{\mathrm{t} 1} \\
P_{\mathrm{t} 2}
\end{array}\right\}=\frac{\left[\begin{array}{cc}
\delta_{22} & \delta_{12}-\delta_{12}^{\prime} \\
\delta_{21}-\delta_{21}^{\prime} & \delta_{11}
\end{array}\right]}{\delta_{11} \delta_{12}-\left(\delta_{21}^{\prime}-\delta_{21}\right)\left(\delta_{12}^{\prime}-\delta_{12}\right)}\left\{\begin{array}{l}
w_{\mathrm{t} 1} \\
w_{\mathrm{t} 2}
\end{array}\right\},
$$

where $\delta_{11}$ and $\delta_{22}$ represents the flexibility of the test pile and reaction pile due to its loading, respectively; $\delta_{12}$ is the reduction of flexibility of the test pile due to loading on the reaction pile; $\delta_{21}$ is the reduction of flexibility of the reaction pile due to loading on the test pile; $\delta_{12}{ }^{\prime}$ is the reduction of flexibility of the test pile induced by the effects of pile reinforcement in soil due to the adjacent load-free reaction pile; and $\delta_{21}{ }^{\prime}$ is the reduction of flexibility of the reaction pile induced by the effects of pile reinforcement in soil due to the neighbouring load-free test pile.

Assuming $\delta_{11}=\delta_{22}=\delta, \delta_{21}=\delta_{12}=\Delta \delta$, and $\delta_{12}{ }^{\prime}=\delta_{21}{ }^{\prime}$ $=\Delta \delta^{\prime}$, one obtains:

$$
\left\{\begin{array}{l}
P_{\mathrm{t} 1} \\
P_{\mathrm{t} 2}
\end{array}\right\}=\frac{\left[\begin{array}{cc}
\delta & \Delta \delta-\Delta \delta^{\prime} \\
\Delta \delta-\Delta \delta^{\prime} & \delta
\end{array}\right]}{\left(\delta+\Delta \delta^{\prime}-\Delta \delta\right)\left(\delta+\Delta \delta-\Delta \delta^{\prime}\right)}\left\{\begin{array}{l}
w_{\mathrm{t} 1} \\
w_{\mathrm{t} 2}
\end{array}\right\} .
$$

Assuming the displacement at the pile head $w_{\mathrm{t} 1}=1$, we can obtain the stiffness of the types of soil around test pile $k^{*}=P_{\mathrm{t} 1}$, whereas the pile head displacement of reaction pile $w_{\mathrm{t} 2}$ is assumed to be 1 , and the stiffness of the soil types around the reaction pile is defined by $k^{*}{ }^{\prime}=P_{\mathrm{t} 2}$. By substituting the abovementioned information into Eq. (18), the stiffness of the soil around test pile and reaction pile can be calculated as

$$
k^{*}=k^{* \prime}=\frac{1}{\delta+\Delta \delta^{\prime}-\Delta \delta} .
$$

The flexibility of the test pile (reaction pile) due to its loading, $\delta$, is given as (Randolph and Wroth, 1979)

$$
\delta=\frac{1}{2 \pi G} \ln \left(\frac{r_{\mathrm{m}}}{r_{0}}\right) .
$$

In a pile group with one test pile and four reaction piles, $r_{\mathrm{m}}$ is assumed to be identical to the value adopted for a single pile. This assumption is acceptable as proposed by Lee and Xiao (2001).

The reduction in flexibility of test pile (reaction piles) due to loading on reaction pile (test pile), $\Delta \delta$, is given as follows:

$$
\Delta \delta=\frac{1}{2 \pi G} \ln \left(\frac{r_{\mathrm{m}}}{r_{0}}\right) \cdot \xi
$$


where $\xi$ is an attenuation coefficient of the displacement of the soil around pile shaft as the center-tocenter distance between piles increases, as suggested by Randolph and Wroth (1979):

$$
\xi=\frac{\ln r_{\mathrm{m}}-\ln s}{\ln r_{\mathrm{m}}-\ln r_{0}}
$$

where $s$ is the center-to-center distance between reaction piles and test pile.

Eq. (22) can be rearranged into:

$$
\Delta \delta=\frac{1}{2 \pi G} \ln \left(\frac{r_{\mathrm{m}}}{s}\right) .
$$

The reduction in flexibility of the test pile (reaction pile) induced by the effects of pile reinforcement in different soil types due to the adjacent load-free reaction pile (test pile), $\Delta \delta^{\prime}$, can be predicted by (Shi et al., 2003):

$$
\Delta \delta^{\prime}=\frac{1}{4 \pi G} \frac{r_{0}}{S} \ln \left(\frac{r_{\mathrm{m}}}{S}\right)
$$

The stiffness of the soil around test pile, $k^{*}$, is assumed to be identical to the stiffness of the soil around reaction pile, $k^{* \prime}$. The values of $k^{*}$ and $k^{* \prime}$ can be calculated by

$$
k^{*}=k^{* \prime}=\frac{4 \pi s G}{2 s \ln \left(\frac{s}{r_{0}}\right)+r_{0} \ln \left(\frac{r_{\mathrm{m}}}{s}\right)} .
$$

Note that for the test pile embedded in a multilayered soil with the influence of four reaction piles, the load applied on the test pile is $P_{\mathrm{tl}}$, whereas each reaction pile is loaded $0.25 P_{\mathrm{t} 1}$ in the opposite direction. As stated earlier, the center-to-center distance between each reaction pile and test pile is assumed to be identical. The influence of four reaction piles with each reaction pile loaded $0.25 P_{\mathrm{t} 1}$ on the stiffness of the soil around the test pile can be assumed to be equivalent to the effect of one reaction pile loaded $P_{\mathrm{t} 1}$ on the stiffness of the soil. Therefore, the stiffness of the soil around test pile with the influence of four reaction piles, $k^{*}$, can be predicted using Eq. (25), while the initial pile head stiffness of the test pile with the influence of four reaction piles, $K_{\mathrm{i}}$, can be estimated by Eq. (14). The correction factor $F_{\mathrm{c}}$ is adopted to account for the influence of reaction piles. The smaller value of $F_{\mathrm{c}}$ suggests that smaller errors arise in the measured settlement of the test pile.

\section{Comparison of computed results derived from the present approach with that esti- mated from a computer program, PRAB}

To verify the reliability of the present approach, the above-mentioned approach is used to analyze the test pile embedded in two soil profiles reported by Kitiyodom et al. (2004), as shown in Fig. 3. Comparisons of results are made between the proposed approach and the program PRAB (Kitiyodom et al., 2004) for both cases. Note that the emphases of both cases are focused on the relationship between load and displacement (initial pile head stiffness) where the subsoil behaves linear elastically.

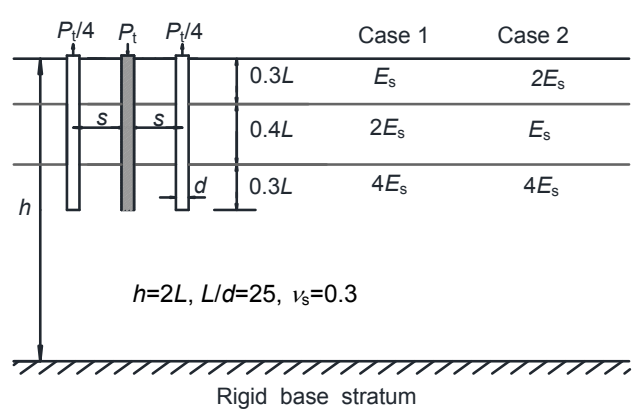

Fig. 3 Test pile embedded in a multilayered soil

Fig. 4 shows that the value of correction factor $F_{\mathrm{c}}$ decreases as the pile spacing ratio, $s / d$ increases, and increases with increasing pile soil stiffness, $E_{\mathrm{p}} / E_{\mathrm{s}}$. The calculated values of $F_{\mathrm{c}}$ of the test pile embedded in case 1 soil profile are slightly smaller than that in case 2 soil profile. Comparisons of results estimated from the present method and the analytical program PRAB for both cases indicate that they are in good agreement with each other when the pile soil stiffness $E_{\mathrm{p}} / E_{\mathrm{s}}$ is small, i.e., $E_{\mathrm{p}} / E_{\mathrm{s}}=100$. Furthermore, the differences between them increase with an increase in pile soil stiffness because the influence of the sheltering effect between reaction piles and test pile on the initial test pile head stiffness is taken into account in the present approach. In general, the calculated values of $F_{\mathrm{c}}$ are smaller than the values of $F_{\mathrm{c}}$ 
estimated from the analytical program PRAB where $E_{\mathrm{p}} / E_{\mathrm{s}}>100$.

It can be concluded that even for the case where a pile spacing ratio is adopted as four (in line with recommendations of (JGJ 106-2003)), the correction factor may be 1.28 to 1.33 where $100<E_{\mathrm{p}} / E_{\mathrm{s}}<1000$. This suggests that the measured settlement in these cases may be 0.75 to 0.78 times the individual pile displacement. This leads to a great underestimation of the test pile settlement if the influence of the reaction piles in a static load test is neglected.
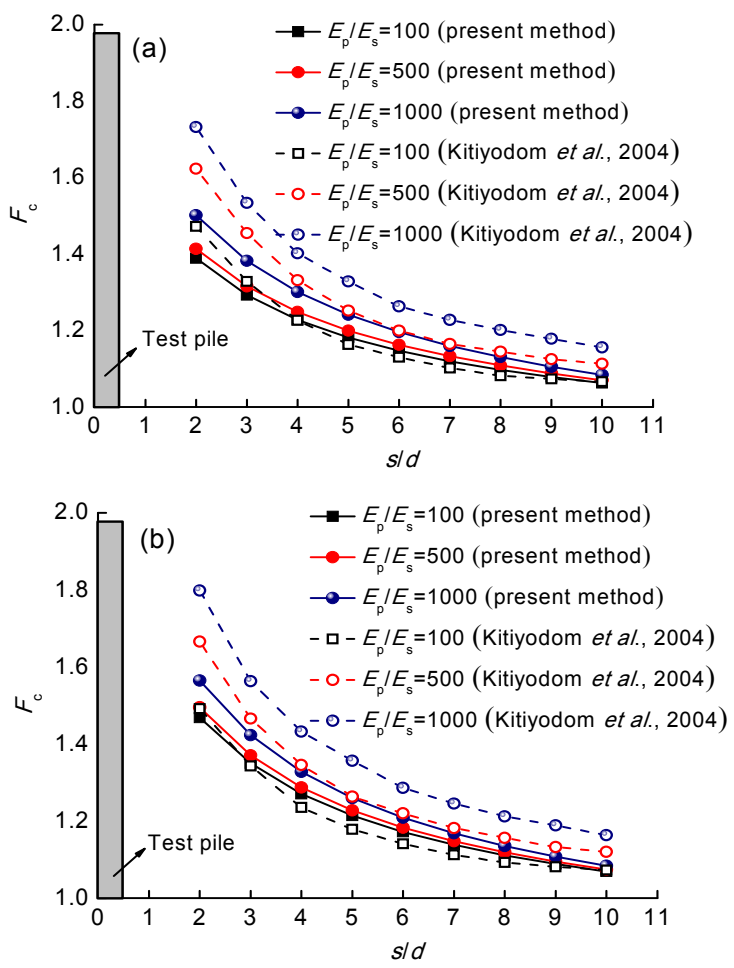

Fig. 4 Correction factor, $F_{c}$, for test pile embedded in multilayered soils $\left(h / L=2, v_{\mathrm{s}}=0.30\right.$ and $\left.L / d=25\right)$

(a) Case 1; (b) Case 2

\section{Nonlinear response of a single pile em- bedded in a multilayered soil}

To consider nonlinear behavior of the soil around the pile shaft, a hyperbolic relationship between shear strain and shear stress is employed, as suggested by Kraft et al. (1981) and Chow (1986). The tangent shear modulus of the soil, $G_{\mathrm{t}}$, is predicted by

$$
G_{\mathrm{t}}=G_{\mathrm{i}}\left(1-\frac{R_{\mathrm{fs}} \tau}{\tau_{\mathrm{f}}}\right)^{2}
$$

where $G_{\mathrm{i}}$ is the initial shear modulus of the soil around pile; $\tau$ is the shear stress; $\tau_{\mathrm{f}}$ is the limiting shear stress; and $R_{\mathrm{fs}}$ is a fitting constant of the hyperbolic curve for the surrounding soil.

Substituting Eq. (26) into Eq. (13), the soil stiffness at the pile base, $k_{\mathrm{b}}{ }^{*}$, is estimated as follows:

$$
k_{\mathrm{b}}^{*}=\frac{4 G_{\mathrm{bi}} r_{0}}{\left(1-v_{\mathrm{b}}\right)} \frac{1}{\left[1-\mathrm{e}^{-h^{*} /\left(2 r_{0}\right)}\right]} \times\left(1-\frac{R_{\mathrm{fb}} P_{\mathrm{b}}}{P_{\mathrm{f}}}\right)^{2},
$$

where $G_{\mathrm{bi}}$ is the initial shear modulus of the soil at the pile base, $P_{\mathrm{b}}$ is the mobilized base load; $P_{\mathrm{f}}$ is the ultimate base load, and $R_{\mathrm{fb}}$ is a fitting constant of the hyperbolic curve for the soil around pile base.

The spring stiffness of the soil around the pile shaft can be calculated as follows:

$$
k^{\prime}=\frac{2 \pi G_{\mathrm{i}}}{\ln \left(\frac{r_{\mathrm{m}}-\beta}{r_{0}-\beta}\right)+\frac{\beta\left(r_{\mathrm{m}}-r_{0}\right)}{\left(r_{\mathrm{m}}-\beta\right)\left(r_{0}-\beta\right)}},
$$

where $\beta=\tau_{0} r_{0} R_{\mathrm{fs}} / \tau_{\mathrm{f}}$.

Substituting Eqs. (27) and (28) into Eq. (14), the nonlinear stiffness of a single pile, $K_{i}^{\prime}$, can be estimated.

\section{Nonlinear response of an influenced test pile embedded in a multilayered soil}

Considering nonlinear behavior of the surrounding soil, the flexibility of the test pile (reaction pile) due to its loading, $\delta^{*}$, can be calculated as

$$
\delta^{*}=\frac{1}{2 \pi G}\left[\ln \left(\frac{r_{\mathrm{m}}-\beta}{r_{0}-\beta}\right)+\frac{\beta\left(r_{\mathrm{m}}-r_{0}\right)}{\left(r_{\mathrm{m}}-\beta\right)\left(r_{0}-\beta\right)}\right]
$$

The reduction in flexibility of the test pile (reaction piles) due to loading on the reaction pile (test pile), $\Delta \delta^{*}$, is given as follows:

$$
\Delta \delta^{*}=\frac{\xi^{*}}{2 \pi G}\left[\ln \left(\frac{r_{\mathrm{m}}-\beta}{r_{0}-\beta}\right)+\frac{\beta\left(r_{\mathrm{m}}-r_{0}\right)}{\left(r_{\mathrm{m}}-\beta\right)\left(r_{0}-\beta\right)}\right],
$$

where 


$$
\xi^{*}=\frac{\ln \left(\frac{r_{\mathrm{m}}-\beta}{s-\beta}\right)+\frac{\beta\left(r_{\mathrm{m}}-s\right)}{\left(r_{\mathrm{m}}-\beta\right)(s-\beta)}}{\ln \left(\frac{r_{\mathrm{m}}-\beta}{r_{0}-\beta}\right)+\frac{\beta\left(r_{\mathrm{m}}-r_{0}\right)}{\left(r_{\mathrm{m}}-\beta\right)\left(r_{0}-\beta\right)}}
$$
form:

Eq. (30) can be rearranged into the following

$$
\Delta \delta^{*}=\frac{1}{2 \pi G}\left[\ln \left(\frac{r_{\mathrm{m}}-\beta}{s-\beta}\right)+\frac{\beta\left(r_{\mathrm{m}}-s\right)}{\left(r_{\mathrm{m}}-\beta\right)(s-\beta)}\right] .
$$

The reduction in flexibility of the test pile (reaction pile) induced by the effects of pile reinforcement in soil due to the adjacent load-free reaction pile (test pile), $\Delta \delta^{*}$, can be predicted by

$$
\Delta \delta^{* \prime}=\frac{1}{4 \pi G} \frac{r_{0}}{s}\left[\ln \left(\frac{r_{\mathrm{m}}-\beta}{s-\beta}\right)+\frac{\beta\left(r_{\mathrm{m}}-s\right)}{\left(r_{\mathrm{m}}-\beta\right)(s-\beta)}\right] .
$$

Considering the nonlinear behavior of the soil around the pile shaft, the stiffness of the soil around test pile, $k^{* *}$, is identical to the stiffness of the soil around reaction pile, $k^{* * *}$. The values of $k^{* *}$ and $k^{* *}$, can be calculated by

$$
\begin{aligned}
k^{* * *}=k^{* * \prime}= & 4 \pi G s /\left\{2 s\left[\ln \left(\frac{s-\beta}{r_{0}-\beta}\right)+\frac{\beta\left(s-r_{0}\right)}{\left(r_{0}-\beta\right)(s-\beta)}\right]\right. \\
& \left.+r_{0}\left[\ln \left(\frac{r_{\mathrm{m}}-\beta}{s-\beta}\right)+\frac{\beta\left(r_{\mathrm{m}}-s\right)}{\left(r_{\mathrm{m}}-\beta\right)(s-\beta)}\right]\right\} .
\end{aligned}
$$

Substituting Eqs. (27) and (34) into Eq. (14), the pile head stiffness of the test pile influenced by four reaction piles can be estimated. Considering the nonlinear response of soil, the correction factor $F_{\mathrm{c}}{ }^{*}$ can then be calculated.

\section{Comparison of the nonlinear response of the test pile with influence of reaction piles estimated from the proposed approach and centrifuge model test}

Two kinds of centrifuge model tests on piles embedded into dense sand were conducted by Latotzke et al. (1997) to analyze the influence of reaction piles on the load-displacement response of the test pile. In the first test, a 220 -mm-long single pile (non-influenced test pile) with a diameter of $30 \mathrm{~mm}$ and an elastic modulus of $27 \mathrm{GPa}$ at model scale was tested to capture the test pile response without any influence. In another test, one test pile (influenced test pile) and four reaction piles were employed to observe the influence of the reaction piles on the test pile response. In this test, the dimension of each reaction pile was identical to that of the test pile, and the center-to-center distance between the test pile and the reaction piles was 4.5 times the test pile diameter. Using a centrifuge acceleration level of 45 , a prototype pile with $1.35-\mathrm{m}$ diameter and 9.9-m length was modeled.

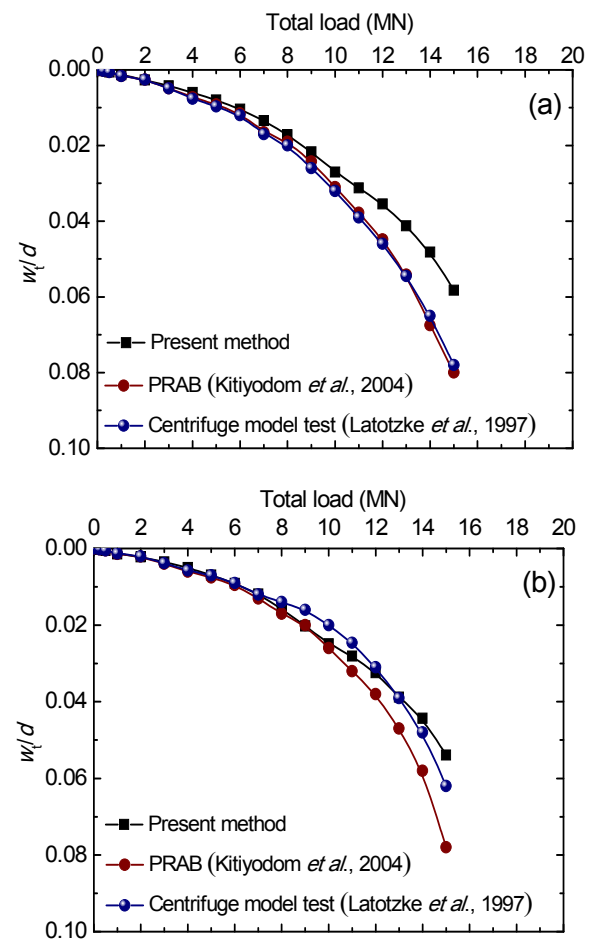

Fig. 5 Comparisons of calculated and measured results of individual (a) and influenced (b) test pile behavior

In this work, the Poisson's ratio of the soil was adopted as 0.30 . Based on the results obtained from the loading test on the single pile, the average shear modulus of the soil was taken as $G_{\text {avg }}=26 \mathrm{MPa}$. The fitting constants of the hyperbolic curve for the soil around the pile shaft and pile base, $R_{\mathrm{fs}}$ and $R_{\mathrm{fb}}$ were set at 0.80 . The ultimate shaft resistance was set at $G_{\text {avg }} / 120$, and the maximum base resistance was assumed to be $14 \mathrm{MPa}$, as suggested by Kitiyodom et al. (2004). 
Comparisons between the measured individual pile displacement and the influenced test pile obtained from the centrifuge model test, as well as that calculated using the present approach along with PRAB (Kitiyodom et al., 2004) are shown in Fig. 5. The calculated results estimated from the present approach are generally in good agreement with the centrifuge model test results. In similar fashion, the calculated results are also in good agreement with the values calculated using PRAB, both in the individual pile and the influenced test pile, especially at low load levels.

\section{Conclusions}

This paper presents a new analytical method to analyze the influence of reaction piles on the test pile response in a static load test. In this proposed method, the interactive effect between soil and pile is simulated using independent springs, and the shear displacement method is also adopted. Furthermore, the influence of the sheltering effect between reaction piles and test pile on test pile behavior is taken into account. The efficiency and accuracy of the present approach is verified using two cases. This method can be easily extended to a nonlinear response of an influenced test pile embedded in a multilayered soil, and the validity is also demonstrated using centrifuge model tests and a computer program presented in the literature.

The present analyses indicate that the measured pile head stiffness of the test pile is greater than the actual pile head stiffness of the individual pile due to the presence of reaction piles. This leads to an underestimation of the test pile settlement in a static load test if the influence of the reaction piles on the test pile response is neglected.

\section{References}

Chow, Y.K., 1986. Analysis of vertically loaded pile groups. International Journal for Numerical and Analytical Methods in Geomechanics, 10(1):59-72. [doi:10.1002/ nag.1610100105]

de Sanctis, L., Mandolini, A., 2006. Bearing capacity of piled rafts on soft clay soils. Journal of Geotechnical and Geoenvironmental Engineering, 132(12):1600-1610. [doi:10. 1061/(ASCE)1090-0241(2006)132:12(1600)]

Guo, W.D., 2001. Pile capacity in nonhomogeneous softening soil. Soils and Foundations, 41(2):111-120. [doi:10. 3208/sandf.41.2_111]

JGJ 106-2003. Technical Code for Testing of Building Foundation Piles. China Construction Industry Press, Beijing, p.22-26 (in Chinese).

Kitiyodom, P., Matsumoto, T., Kanefusa, N., 2004. Influence of reaction piles on the behaviour of a test pile in static load testing. Canadian Geotechnical Journal, 41(3): 408-420. [doi:10.1139/t03-098]

Klar, A., Leung, Y.F., 2009. Simple energy-based method for nonlinear analysis of incompressible pile groups in clays. Journal of Geotechnical and Geoenvironmental Engineering, 135(7):960-965. [doi:10.1061/(ASCE)GT.1943-5 606.0000002]

Kraft, L.M., Ray, R.P., Kagawa, T., 1981. Theoretical development of t-z curves. Journal of Geotechnical Engineering, 107(11):1543-1561.

Latotzke, J., König, D., Jessberger, H.L., 1997. Effects of Reaction Piles in Axial Pile Tests. Proceedings of the 14th International Conference on Soil Mechanics and Foundation Engineering, Hamburg, Germany, 2:1097-1101.

Lee, C.Y., 1991. Discrete layer analysis of axially loaded piles and pile groups. Computers and Geotechnics, 11(4): 295-313. [doi:10.1016/0266-352X(91)90014-7]

Lee, K.M., Xiao, Z.R., 2001. A simplified method for nonlinear analysis of single piles in multilayered soils. Canadian Geotechnical Journal, 38(5):1063-1080. [doi:10. 1139/t01-034]

Lu, K.L., Yang, Y., 2007. Effect of the anchor piles on the static load test result. Journal of Hefei University of Technology (Natural Science), 30(7):892-895 (in Chinese).

Mylonakis, G., Gazetas, G., 1998. Settlement and additional internal forces of grouped piles in layered soil. Géotechnique, 48(1):55-72. [doi:10.1680/geot.1998.48.1.55]

Poulos, H.G., 2001. Piled raft foundations: design and applications. Géotechnique, 51(2):95-113. [doi:10.1680/geot. 2001.51.2.95]

Poulos, H.G., Davis, E.H., 1980. Pile Foundation Analysis and Design. Wiley, New York.

Randolph, M.F., Wroth, C.P., 1978. Analysis of deformation of vertically loaded pile. Journal of the Geotechnical Engineering Division, 104(12):1465-1488.

Randolph, M.F., Wroth, C.P., 1979. An analysis of the vertical deformation of pile groups. Géotechnique, 29(4):423439. [doi:10.1680/geot.1979.29.4.423]

Reul, O., Randolph, M.F., 2003. Piled rafts in overconsolidated clay: comparison of in situ measurements and numerical analysis. Géotechnique, 53(3):301-315. [doi:10.1680/ geot.2003.53.3.301]

Shi, M.L., Deng, X.J., Liu, S.Y., 2003. Study of restrain effect among piles. Journal of Southeast University (Natural Science Edition), 33(2):343-347 (in Chinese).

Xu, K.J., Poulos, H.G., 2001. 3-D elastic analysis of vertical piles subjected to passive loadings. Computers and Geotechnics, 28(5):349-375. [doi:10.1016/S0266-352X(00) 00024-0] 